\title{
Design Optimization of Deep Eutectic Solvent Composition and Separation Performance of Cyclohexane and Benzene Mixtures with Extractive Distillation
}

\author{
Fang Bai ${ }^{1,2,3}$, Chao Hua ${ }^{1,3, *}$, Yongzhi Bai ${ }^{4, *}$ and Mengying Ma 5 \\ 1 Key Laboratory of Green Process and Engineering, Institute of Process Engineering, Chinese Academy of \\ Sciences, Beijing 100190, China; fbai@ipe.ac.cn \\ 2 School of Chemistry and Chemical Engineering, University of Chinese Academy of Sciences, \\ Beijing 100049, China \\ 3 Innovation Academy for Green Manufacture, Chinese Academy of Sciences, Beijing 100190, China \\ 4 China Building Material Test \& Certification Group Beijing, Tian Yu Co., Ltd., Beijing 101113, China \\ 5 School of Chemistry and Environmental Engineering, China University of Mining and Technology (Beijing), \\ Beijing 100083, China; mmy15630467633@163.com \\ * Correspondence: huachao@ipe.ac.cn (C.H.); byz@ctc.ac.cn (Y.B.)
}

Citation: Bai, F.; Hua, C.; Bai, Y.; Ma, M. Design Optimization of Deep Eutectic Solvent Composition and Separation Performance of

Cyclohexane and Benzene Mixtures with Extractive Distillation. Processes 2021, 9, 1706. https://doi.org/ $10.3390 /$ pr9101706

Academic Editors: Weize Wu, Tiancheng Mu and Shuhang Ren

Received: 19 July 2021

Accepted: 31 August 2021

Published: 23 September 2021

Publisher's Note: MDPI stays neutral with regard to jurisdictional claims in published maps and institutional affiliations.

Copyright: (c) 2021 by the authors. Licensee MDPI, Basel, Switzerland. This article is an open access article distributed under the terms and conditions of the Creative Commons Attribution (CC BY) license (https:/ / creativecommons.org/licenses/by/ $4.0 /)$.

\begin{abstract}
Deep eutectic solvents (DESs) have properties that make them suitable candidates to be used as entrainers for extractive distillation. In the previous work, it was proven that DES(1:2) (tetrabutylammonium bromide: levulinic acid, 1:2, molar ratio) can break the cyclohexane-benzene azeotrope. In the present work, the HBA and HBD ratio and molar concentration of DES were optimized to obtain a better constitute and condition of DES to be utilized in cyclohexane and benzene extractive distillation. The physical properties and structure of the prepared DESs were characterized. Vapor-liquid equilibrium data of the ternary system (benzene + cyclohexane + DESs) were also measured at atmospheric pressure. All experimental equilibrium data were correlated with Wilson, nonrandom two-liquid (NRTL), and universal quasichemical (UNIQUAC) activity coefficient models, from which the coefficient of determination (R2) of the three pseudo-ternary systems fitting was calculated. From the obtained results, the best HBA and HBD ratio in the DESs is elucidated as 1:2, the best molar concentration of DES is 0.1 , and the NRTL model predicts the experimental data more accurately than the Wilson and UNIQUAC models. From the derived mechanism, the formation of stronger hydrogen bond and $\pi-\pi$ bond interactions between DES and benzene is obtained when HBA and HBD ratio in DES is 1:2. In other conditions, the azeotrope cannot be broken, or the efficiency is low. The present work provides an environmentally friendly method to separate aromatic/aliphatic mixtures and act as a guide for further study of DESs in extractive distillation.
\end{abstract}

Keywords: deep eutectic solvents; extractive distillation; separation; (vapor + liquid) equilibrium; cyclohexane; benzene

\section{Introduction}

A new family of solvents originally called "deep eutectic solvents" (DESs), which are formed by a hydrogen bond donor (HBD) and a hydrogen bond acceptor (HBA), is proposed by Abbott, firstly, as an appropriate substitute to ILs [1], also called "low transition temperature mixtures" (LTTMs) [2-4]. They possess properties that gain great advantages in the field of mixtures separation, such as liquid-liquid extraction [5-26], extractive distillation [2,27-29], and gas absorption [30].

In the previous work, it was proven that the DES(1:2) (tetrabutylammonium bromide: levulinic acid, 1:2, molar ratio) can break the cyclohexane-benzene azeotrope. In the present paper, the influence of HBA and HBD ratio and molar concentration of DES on the 
extractive effectiveness is studied to obtain the optimum input parameters for cyclohexane and benzene extractive distillation using DES.

In this paper, the HBA and HBD ratio (tetrabutylammonium bromide: levulinic acid) is fixed as 1:1,1:2, 1:3, and 1:4, and the molar concentration of DES is selected as 0.05 , 0.10 .15 , and 0.2. The DESs required for the tests are prepared, and their properties and structures are elucidated. VLE data of the ternary (benzene-cyclohexane-DESs) mixtures have been measured to investigate if the azeotrope can be broken to assess the DESs extraction ability. FT-IR and NMR are used in the study for determining the extractive mechanism.

\section{Materials and Methods}

\subsection{Materials}

The purity and source of all the chemicals used in the present work are listed in Table 1.

Table 1. Chemicals Used in This Work and their Abbreviation.

\begin{tabular}{cccc}
\hline Name & Source & M (g/mol) & Purity \\
\hline Benzene & $\begin{array}{c}\text { Chemical Factory } \\
\text { Engineering and Technology }\end{array}$ & 78.11 & $>99 \%$ \\
Cyclohexane & $\begin{array}{c}\text { Research Center of Guangdong Fine } \\
\text { Chemistry }\end{array}$ & 84.16 & $>99.5 \%$ \\
$\begin{array}{c}\text { Tetrabutylammonium } \\
\text { bromide (TBAB) }\end{array}$ & $\begin{array}{c}\text { Tianjin Fuchen Chemical Reagents } \\
\text { Levulinic acid (LA) }\end{array}$ & $\begin{array}{c}\text { Factory } \\
\text { Xilong Chemical Co., Ltd. }\end{array}$ & 116.12 \\
\hline
\end{tabular}

\subsection{Preparation of DESs}

DESs are prepared by following the procedure reported in the literature [3]. Mixtures are weighed using a Mettler AX205 balance having a precision of $\pm 0.02 \mathrm{mg}$. Both HBD and HBA are added to a flask and are heated under constant stirring. The uncertainty in the molar mixing ratio is $\pm 2 \%$, evaluated based on the uncertainty in the balance reading and the purity of the chemicals used. The synthesized DESs are dried in a vacuum oven at $100{ }^{\circ} \mathrm{C}$ for $24 \mathrm{~h}$. According to the above synthesis method, four kinds of deep eutectic solvents were synthesized using TBAB as a hydrogen bond acceptor and LA as a hydrogen bond donor, as shown in Table 2.

Table 2. DESs used in the present work.

\begin{tabular}{ccccc}
\hline Name & HBA & HBD & Molar Ratio & $\overline{\boldsymbol{M}}$ (g/mol) \\
\hline DES(1:1) & & & $1: 1$ & 219.25 \\
DES(1:2) & TBAB & LA & $1: 2$ & 184.87 \\
DES(1:3) & & & $1: 3$ & 167.685 \\
DES(1:4) & & $1: 4$ & 157.44 \\
\hline
\end{tabular}

\subsection{Characterization of DES}

The melting point and glass transition temperature of the prepared DESs are investigated using differential scanning calorimetry (DSC). DSC analysis is carried out for all the prepared samples using a METTLER TOLEDO Differential Scanning Calorimeter type DSC1. The DSC measurements are performed under a nitrogen $\left(\mathrm{N}_{2}\right)$ atmosphere to prevent oxidation of the samples. The $\mathrm{N}_{2}$ flow rate is fixed as $45 \mathrm{~mL} / \mathrm{min}$, where the continuous heating is carried out at a rate of $10^{\circ} \mathrm{C} \cdot \mathrm{min}^{-1}$ until the specimens are melted completely. Further, the density and viscosity of the synthesized DESs are measured at different temperatures using an Anton Paar, instrument type DMA 5000-AMVn. The structure of chemical constituents and mutual interactions between different constituents are investigated by Fourier-transformed infrared (FT-IR) type T27-Hyperion-Vector22 and nuclear magnetic resonance (NMR) type AVANCE III. 


\subsection{Vapor-Liquid Equilibrium Device}

The Vapor-liquid balance device is shown in Figure 1, and the experimental process is as follows. A $30 \mathrm{~mL}$ aliquot of the liquid mixture is loaded in the equilibrium kettle. Then, the cooling water is turned on, and gradually, the mixture is heated at the beginning stage. The heating power is adjusted in such a way that the return rate of condensed water of 2-3 drops per second is achieved. To stabilize the reflux action, the device is refluxed for $0.5 \mathrm{~h}$, and then, the temperature is noted every $5 \mathrm{~min}$. After $0.5 \mathrm{~h}$ of the stabilization period, the temperature becomes stable, and the liquid and vapor phases are believed to have achieved equilibrium. Then, $0.6 \mu \mathrm{L}$ of the sample from the liquid phase and vapor phase is collected and tested using chromatography. Each test measurement is repeated three times to decline the test error. As the outlet of the condenser shown in the sketch map is connected with the outside ambient atmosphere, the pressure in the VLE experiment is kept at atmospheric pressure.

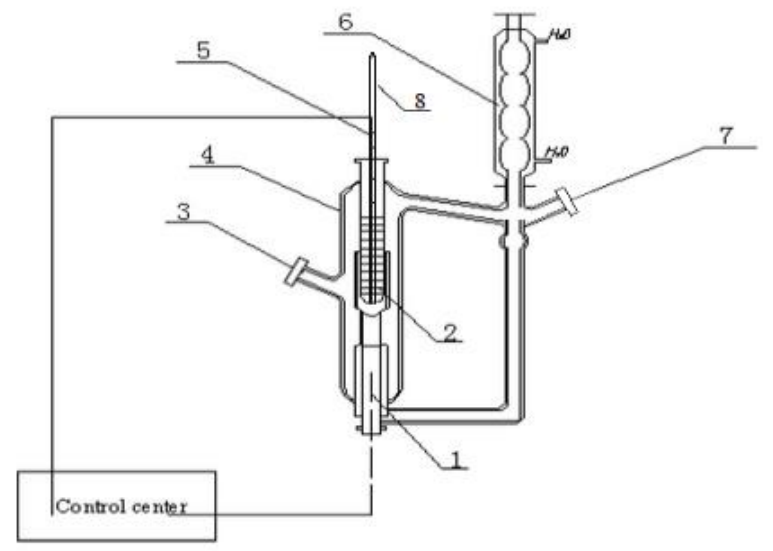

Figure 1. Constant pressure double circulation vapor-liquid equilibrium kettle. 1-heater rod; 2-thermometer sleeve tube; 3-liquid phase sample connection; 4-liquid phase sample connection; 5-thermal resistance; 6-condenser; 7-vapor phase sample connection; 8-mercury thermometer.

The samples are analyzed using chromatography with an FID detector employing the programmed temperature technique. The initial column temperature is kept at $50{ }^{\circ} \mathrm{C}$ for $1 \mathrm{~min}$. Then, it is heated to $220^{\circ} \mathrm{C}$ at a heating rate of $10^{\circ} \mathrm{C} \cdot \mathrm{min}^{-1}$ and held for $10 \mathrm{~min}$. The gasification chamber temperature is maintained at $220^{\circ} \mathrm{C}$, where the temperature of the detector is $250{ }^{\circ} \mathrm{C}$, to which high purity $\mathrm{N}_{2}$ as a carrier gas is introduced with a flow rate of $30 \mathrm{~mL} \cdot \mathrm{min}^{-1}$. Further, hydrogen and air are introduced with flow rates of $30 \mathrm{~mL} \cdot \mathrm{min}^{-1}$ and $300 \mathrm{~mL} \cdot \mathrm{min}^{-1}$, respectively. Gas chromatographic parameters are shown in Table 3.

Table 3. GC conditions employed for analysis of the condensed vapor phase.

\begin{tabular}{cc}
\hline Condition & Parameter \\
\hline Column type & KB-FFAP $(30 \mathrm{~m} ; 0.32 \mathrm{~mm} ; 0.25 \mu \mathrm{m})$ \\
Detector type & FID \\
Detector temperature & $523 \mathrm{~K}$ \\
Injector temperature & $503 \mathrm{~K}$ \\
Injection volume & $0.4 \mathrm{uL}$ \\
Carrier gas & $\mathrm{N}_{2}$ \\
Flow rate (constant) & $30 \mathrm{~cm}^{3} \cdot \mathrm{min}^{-1}$ \\
Split ratio & 200 \\
\hline
\end{tabular}

\section{Results and Discussion}

\subsection{DESs Characterization}

The melting point and glass transition temperature values evaluated for the four DESs are summarized in Table 4 . The density and the viscosity of the four DESs are measured 
at atmospheric pressure in the temperature range from $T / K=293.15$ to 353.15 , with a step increase of $10 \mathrm{~K}$. The experimental values for the density and the viscosity at different temperatures are tabulated in Table 5. To study the interactions that exist in HBA and HBD, the FT-IR analysis is carried out for DESs, HBD, and HBA.

Table 4. Glass transition temperature and melting point of the DESs.

\begin{tabular}{cccc}
\hline Sample & $\begin{array}{c}\text { The Glass Transition } \\
\text { Temperature }\left({ }^{\circ} \mathbf{C}\right)\end{array}$ & $\begin{array}{c}\text { Melting Point of } \\
\text { HBA }\left({ }^{\circ} \mathbf{C}\right)\end{array}$ & $\begin{array}{c}\text { Melting Point of } \\
\text { HBD }\left({ }^{\circ} \mathbf{C}\right)\end{array}$ \\
\hline DES(1:1) & $\sim 30-\sim 25$ & & \\
DES(1:2) & $\sim 70-\sim 65$ & $102-106$ & 37.2 \\
DES(1:3) & $\sim 60-\sim 50$ & & \\
DES(1:4) & $\sim 80-\sim 70$ & & \\
\hline
\end{tabular}

Table 5. Experimental density and viscosity values at different temperatures and atmospheric pressures $(p=101.325 \mathrm{kPa})$.

\begin{tabular}{|c|c|c|c|c|c|c|c|c|}
\hline \multirow{2}{*}{ Temperature (K) } & \multicolumn{4}{|c|}{ Density $\left(\mathrm{g} / \mathrm{cm}^{3}\right)$} & \multicolumn{4}{|c|}{ Viscosity (mPa.s) } \\
\hline & 1:1 & $1: 2$ & $1: 3$ & $1: 4$ & 1:1 & $1: 2$ & $1: 3$ & $1: 4$ \\
\hline 293.15 & - & 1.0979 & 1.1050 & 1.1118 & - & 964.58 & 483.46 & 291.14 \\
\hline 303.15 & - & 1.0909 & 1.0982 & 1.1045 & - & 426.89 & 223.73 & 142.22 \\
\hline 313.15 & - & 1.0843 & 1.0912 & 1.0974 & - & 206.48 & 116.34 & 77.47 \\
\hline 323.15 & 1.0639 & 1.0799 & 1.0840 & 1.0906 & 372.82 & 114.54 & 67.99 & 46.53 \\
\hline 333.15 & 1.0589 & 1.0707 & 1.0770 & 1.0828 & 201.73 & 68.30 & 42.80 & 30.11 \\
\hline 343.15 & 1.0523 & 1.0643 & 1.0703 & 1.0757 & 116.36 & 43.41 & 28.77 & 20.94 \\
\hline 353.15 & 1.0466 & 1.0572 & 1.0631 & 1.0680 & 72.438 & 29.79 & 20.57 & 15.21 \\
\hline
\end{tabular}

All the prepared DESs display a glass transition temperature, i.e., when the temperature reaches lower than their freezing point, they become supercooled liquids instead of undergoing crystallization process, and finally, they transform into a glassy state. The melting point of the pure HBD component, which forms DES, has a lower melting point, and therefore, all the glass transition temperatures of DES are compared with the melting point of HBD. The glass transition temperatures of all DES are lower than the melting point of HBD, substantiating that the hydrogen bonding is formed in the prepared DESs, which is very essential. The glass transition temperature of DES(1:4) is the least of all the DESs, indicating that the hydrogen bonds that exist in $\operatorname{DES}(1: 4)$ are the strongest.

The density of DES(1:1-1:4) is measured under different temperatures (293.15-353.15 K) under atmospheric pressure. As DES(1:1) is not in the liquid state at room temperature, it is measured from $323.15 \mathrm{~K}$ (Figure 2). From the figure, it is inferred that within the temperature range of 293.15 to $353.15 \mathrm{~K}$, the densities of the samples are found to cover the range between 1.04 and $1.12 \mathrm{~g} / \mathrm{cm}^{3}$, which is close to the density of water, and also, the density tends to decrease with an increase in temperature. The obtained results follow the general liquid density characteristic. Further, with the increase in HBD content, the density increases. 


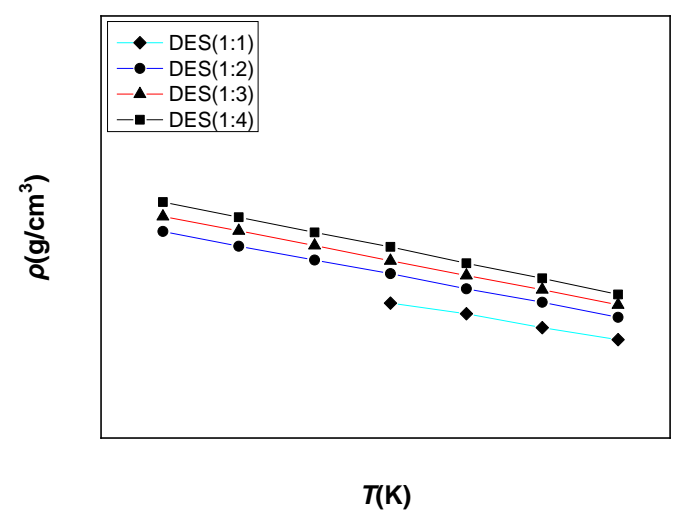

Figure 2. The change in experimental density with respect to temperature for the prepared DESs.

The viscosity of DES(1:1-1:4) was measured under different temperatures between 293.15 and $353.15 \mathrm{~K}$ at atmospheric pressure. Since DES(1:1) is not in the liquid state at room temperature, its viscosity is measured from 323.15 K (Figure 3). From Figure 3, it is inferred that between 293.15 and $353.15 \mathrm{~K}$, the viscosity values of DES are found in the range from 1000 to $10 \mathrm{mPa} \cdot \mathrm{s}$, which follows the same trend as observed in the ionic liquid. Till the temperature is $333.15 \mathrm{~K}$, the viscosity decreases enormously with each step increase in temperature rise. After reaching $333.15 \mathrm{~K}$, the change in viscosity is slow, showing a gradual decrease. Furthermore, it is to be noted that with the increase in HBD content, the density decreases.

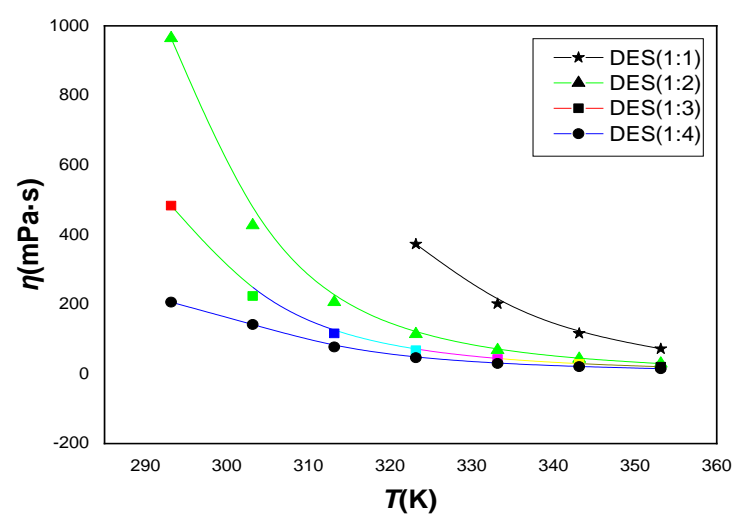

Figure 3. The change in experimental viscosity values of prepared DESs with temperature.

In Figure 4, the FT-IR spectra of LA, TBAB, and DESs display the hydroxy peak $\mathrm{v}(\mathrm{OH})$ at $3200 \mathrm{~cm}^{-1}$. Compared to LA, the peak intensity becomes stronger and wider in DES(1:1-1:4) and is shifted to $3000 \mathrm{~cm}^{-1}$. These interpretations show that the hydrogen bonds are formed between LA and TBAB since there are active hydrogens in LA that can act as HBD and high electron density in the Br atom of TBAB that can act as HBA. At different HBD and HBA ratios, the hydroxy peak intensity strength and width are different, which substantiates that the strength of the hydrogen bond is different for DES(1:1-1:4) and is developed by different ratios. 


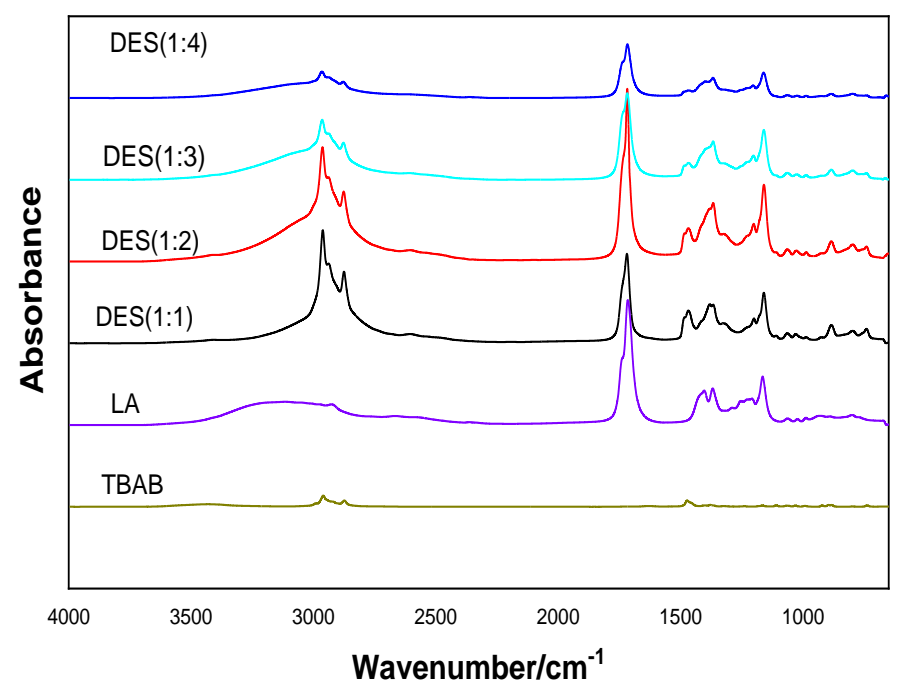

Figure 4. FT-IR spectra of LA, TBAB, and DESs formed by LA and TBAB with a 1:1-1:4 mol ratio.

\subsection{Selection of $H B A$ and $H B D$ Ratio}

\subsubsection{VLE Experiment}

A series of DESs developed using LA and TBAB at different mole ratios, including 1:1, $1: 2,1: 3$, and 1:4, are used to separate the azeotrope (cyclohexane + benzene) at $101.325 \mathrm{kPa}$ where the mole concentration of DESs is fixed as 0.1 .

For a better understanding of the pseudo-ternary VLE behavior, both relative volatility $\left(a_{i j}\right)$ and selectivity $(S)$ are assessed using the following expressions:

$$
\begin{gathered}
\alpha_{i j}=\frac{\frac{y_{i}}{x_{i}}}{\frac{y_{j}}{x_{j}}} \\
S=\frac{\alpha_{i j}^{\text {with entrainer }}}{\alpha_{i j}^{\text {without entrainer }}}
\end{gathered}
$$

where $y$ is the molar fraction of the vapor phase, $x$ the molar fraction of the liquid phase, and the subscripts $i$ and $j$ refer to the more volatile component (cyclohexane) and the less volatile component (benzene), respectively. The estimated relative volatility and selectivity values are provided in Table 6.

Table 6 summarizes the Vapor-liquid equilibrium data of the pseudo-ternary systems cyclohexane (1) + benzene (2) + DES (3) at a pressure of $101.325 \mathrm{kPa}$, where $X_{3}$ is the DES molar fraction in the liquid phase, $X_{1}$ is the cyclohexane molar fraction in the liquid phase, $X^{\prime}{ }_{1}$ is the DES-free cyclohexane molar fraction in the liquid phase, $Y_{1}$ is the cyclohexane molar fraction in the vapor phase, $T$ is the temperature, $\alpha_{i j}$ is the relative volatility, and $S$ is the selectivity. 
Table 6. Vapor-liquid equilibrium data of the pseudo-ternary systems (cyclohexane (1) + benzene (2) + DES (3)).

\begin{tabular}{|c|c|c|c|c|c|c|}
\hline \multicolumn{7}{|c|}{ Cyclohexane (1) + Benzene (2) + DES(1:1)(3), at $101.325 \mathrm{kPa}$} \\
\hline$X_{3}$ & $X_{1}$ & $X^{\prime}{ }_{1}$ & $Y_{1}$ & $T / K$ & $\alpha_{i j}$ & $S$ \\
\hline 0.1 & 0.0000 & 0.0000 & 0.0000 & 353.25 & - & - \\
\hline 0.1 & 0.0652 & 0.0724 & 0.0964 & 352.80 & 1.3670 & 1.0081 \\
\hline 0.1 & 0.0952 & 0.1058 & 0.1448 & 352.27 & 1.4310 & 1.0950 \\
\hline 0.1 & 0.1470 & 0.1633 & 0.2134 & 351.63 & 1.3895 & 1.1049 \\
\hline 0.1 & 0.2525 & 0.2805 & 0.3206 & 351.05 & 1.2106 & 1.0446 \\
\hline 0.1 & 0.3909 & 0.4343 & 0.4307 & 350.73 & 0.9852 & 0.8878 \\
\hline 0.1 & 0.5058 & 0.5620 & 0.5348 & 350.69 & 0.8961 & 0.8075 \\
\hline 0.1 & 0.5867 & 0.6519 & 0.6098 & 350.77 & 0.8346 & 0.9602 \\
\hline 0.1 & 0.6807 & 0.7563 & 0.7265 & 351.33 & 0.8561 & 1.0402 \\
\hline 0.1 & 0.7461 & 0.8290 & 0.8023 & 351.77 & 0.8371 & 1.0764 \\
\hline 0.1 & 0.7778 & 0.8642 & 0.8452 & 352.20 & 0.8580 & 1.1699 \\
\hline 0.1 & 0.9000 & 1.0000 & 1.0000 & 353.85 & - & - \\
\hline \multicolumn{7}{|c|}{ Cyclohexane (1) + Benzene (2) + DES(1:2), at $101.325 \mathrm{kPa}$} \\
\hline$X_{3}$ & $X_{1}$ & $X_{1}^{\prime}$ & $Y_{1}$ & $T / K$ & $\alpha_{i j}$ & $S$ \\
\hline 0.1 & 0.0000 & 0.0000 & 0.0000 & 353.25 & - & - \\
\hline 0.1 & 0.1668 & 0.1853 & 0.3191 & 351.20 & 2.0601 & 1.7051 \\
\hline 0.1 & 0.2406 & 0.2673 & 0.4939 & 350.64 & 2.6752 & 2.4107 \\
\hline 0.1 & 0.3015 & 0.3351 & 0.6053 & 351.28 & 3.0438 & 3.6984 \\
\hline 0.1 & 0.3529 & 0.3921 & 0.7107 & 351.74 & 3.8089 & 4.8976 \\
\hline 0.1 & 0.4507 & 0.5008 & 0.8091 & 352.34 & 4.2229 & 5.7580 \\
\hline 0.1 & 0.5597 & 0.6219 & 0.8868 & 352.67 & 4.7632 & 6.4947 \\
\hline 0.1 & 0.7232 & 0.8035 & 0.9420 & 353.17 & 3.9681 & 5.4106 \\
\hline 0.1 & 0.9000 & 1.0000 & 1.0000 & 353.85 & - & - \\
\hline \multicolumn{7}{|c|}{ Cyclohexane (1) + Benzene (2) + DES(1:3), at $101.325 \mathrm{kPa}$} \\
\hline$X_{3}$ & $X_{1}$ & $X^{\prime}{ }_{1}$ & $Y_{1}$ & $T / K$ & $\alpha_{i j}$ & $S$ \\
\hline 0.1 & 0.0000 & 0.0000 & 0.0000 & 353.25 & - & - \\
\hline 0.1 & 0.0395 & 0.0439 & 0.0543 & 352.47 & 1.2522 & 0.9581 \\
\hline 0.1 & 0.0902 & 0.1002 & 0.1123 & 351.80 & 1.1360 & 0.9033 \\
\hline 0.1 & 0.1430 & 0.1589 & 0.1725 & 351.28 & 1.1034 & 0.9133 \\
\hline 0.1 & 0.2686 & 0.2984 & 0.3190 & 350.67 & 1.1015 & 0.9926 \\
\hline 0.1 & 0.4313 & 0.4793 & 0.5013 & 350.36 & 1.0924 & 1.0794 \\
\hline 0.1 & 0.5557 & 0.6174 & 0.6031 & 350.59 & 0.9414 & 1.0275 \\
\hline 0.1 & 0.6402 & 0.7114 & 0.7001 & 351.35 & 0.9473 & 1.2181 \\
\hline 0.1 & 0.7217 & 0.8019 & 0.7875 & 352.27 & 0.9157 & 1.2486 \\
\hline 0.1 & 0.7629 & 0.8477 & 0.8256 & 352.71 & 0.8505 & 1.1597 \\
\hline 0.1 & 0.8741 & 0.9712 & 0.9541 & 353.60 & 0.6164 & 0.8405 \\
\hline 0.1 & 0.9000 & 1.0000 & 1.0000 & 353.85 & - & - \\
\hline \multicolumn{7}{|c|}{ Cyclohexane (1) + Benzene (2) + DES(1:4), at $101.325 \mathrm{kPa}$} \\
\hline$X_{3}$ & $X_{1}$ & $X^{\prime}{ }_{1}$ & $Y_{1}$ & $T / K$ & $\alpha_{i j}$ & $S$ \\
\hline 0.1 & 0.0000 & 0.0000 & 0.0000 & 353.25 & - & - \\
\hline 0.1 & 0.0921 & 0.1024 & 0.1852 & 352.50 & 1.9930 & 1.5250 \\
\hline 0.1 & 0.1325 & 0.1472 & 0.2577 & 352.10 & 2.0114 & 1.5391 \\
\hline 0.1 & 0.2071 & 0.2302 & 0.4174 & 351.20 & 2.3966 & 1.9836 \\
\hline 0.1 & 0.2550 & 0.2834 & 0.5197 & 350.77 & 2.7368 & 2.3615 \\
\hline 0.1 & 0.3356 & 0.3729 & 0.5713 & 350.97 & 2.2410 & 2.7230 \\
\hline 0.1 & 0.5201 & 0.5779 & 0.6318 & 351.08 & 1.2535 & 1.5231 \\
\hline 0.1 & 0.5913 & 0.6570 & 0.6728 & 351.33 & 1.0737 & 1.3046 \\
\hline 0.1 & 0.6516 & 0.7240 & 0.7086 & 351.60 & 0.9267 & 1.1916 \\
\hline 0.1 & 0.7583 & 0.8425 & 0.8016 & 352.17 & 0.7554 & 1.0300 \\
\hline 0.1 & 0.8252 & 0.9169 & 0.8779 & 352.85 & 0.6516 & 0.8885 \\
\hline 0.1 & 0.9000 & 1.0000 & 1.0000 & 353.85 & - & - \\
\hline
\end{tabular}


At the azeotropic point, the value of the relative volatility is found to be one, which means that both the components in the mixture have the same vapor pressure. As the boiling points of the two components are close to each other, the relative volatility of the two components can be increased by adding a low eutectic solvent. Table 7 and Figures 5-8 depict that when the four DESs are added separately, as entrainers in a molar fraction of 0.1 , only the relative volatility $\left(a_{i j}\right)$ of the system added with $\operatorname{DES}(1: 2)$ is higher than one at all concentrations, while the relative volatility of the other three systems is not higher than one at all concentrations. This phenomenon is attributed to the fact that the $\operatorname{DES}(1: 2)$ breaks the azeotrope, whereas DES(1:1), DES(1:3), and DES(1:4) cannot break it. It also depicts the same results. The pseudo-ternary system added with DES(1:1) and DES(1:3) show the same azeotropic point as the binary system validating that the DES (TBAB:LA) (1:2) and DES (ChCl:LA) (1:2) have no influence on the azeotrope. Although the azeotropic point in the pseudo-ternary system added with DES(1:4) is changed to the cyclohexane side, the azeotrope is not broken. With these data, it is clear that only DES(1:2) acts as an effective entrainer in the present work.

Table 7. Coefficient of determination $\left(\mathrm{R}^{2}\right)$ of the pseudo-ternary systems fitted using the three thermodynamic models.

\begin{tabular}{cccc}
\hline \multirow{2}{*}{ System } & \multicolumn{2}{c}{$\mathbf{R}^{\mathbf{2}}$} & UNIOUAC \\
\cline { 2 - 4 } & NRTL & WILSON & 0.999206835 \\
cyclohexane-benzene-DES(1:1) & 0.999990073 & 0.999050672 & 0.823243826 \\
cyclohexane-benzene-DES(1:2) & 0.876057425 & 0.615250142 & 0.999021115 \\
cyclohexane-benzene-DES(1:3) & 0.999428449 & 0.99838839 & 0.889570028 \\
cyclohexane-benzene-DES(1:4) & 0.999999997 & 0.885377491 & \\
\hline
\end{tabular}



Figure 5. Experimental and calculated data $X^{\prime} Y$ diagram for cyclohexane (1) + benzene (2) + DES(1:1) (3) at constant pressure $(101.325 \mathrm{kPa})$ and constant DES molar fraction $\left(X_{3}=0.1\right)$.

\subsubsection{VLE Data Correlation}

The local composition activity coefficient models UNIQUAC, WILSON, and NRTL are used for regression analysis of the VLE data of three ternary systems. For each system, the coefficient of determination is estimated to perceive the goodness of fit of the models. The obtained results are provided in Table 7. In the systems containing DES(TBAB:LA) (1:2) and DES(ChCl:LA) (1:2) [31], the prediction is satisfactory as the coefficient of determination is $>0.99$ assessed from all the three models. In the system containing DES(TBAB:LA) (1:2), the prediction is not satisfactory since the coefficient of determination is $<0.99$ using the three models. 


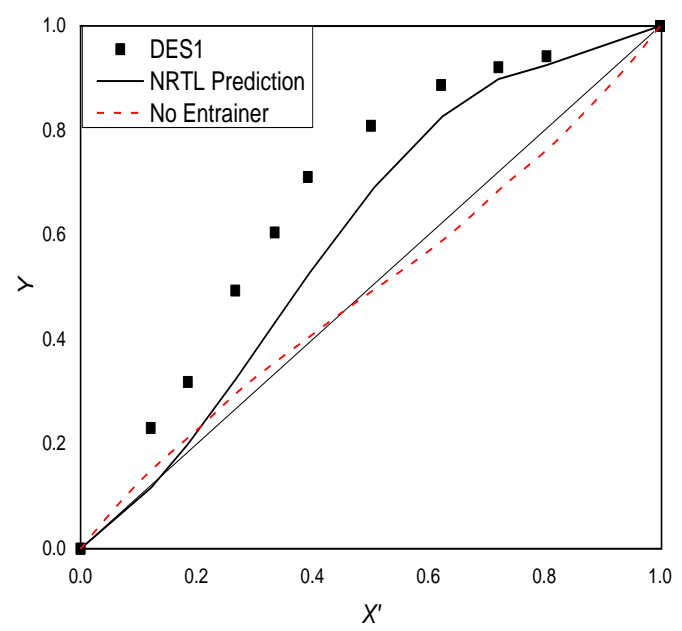

Figure 6. Experimental and calculated data $\mathrm{X}^{\prime} Y$ diagram for cyclohexane (1) + benzene (2) + DES(1:2) (3) at constant pressure $(101.325 \mathrm{kPa})$ and constant DES molar fraction $\left(X_{3}=0.1\right)$.

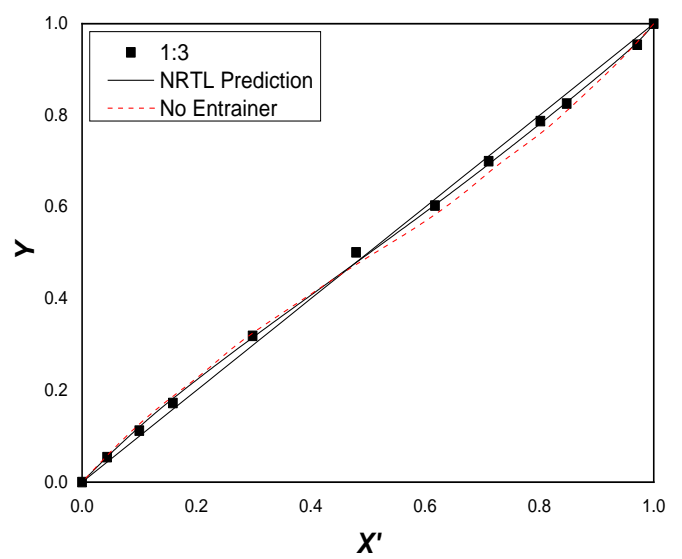

Figure 7. Experimental and calculated data $X^{\prime} Y$ diagram for cyclohexane (1) + benzene (2) + DES(1:3) (3) at constant pressure $(101.325 \mathrm{kPa})$ and constant DES molar fraction $\left(X_{3}=0.1\right)$.



Figure 8. Experimental and calculated data $X^{\prime} Y$ diagram for cyclohexane (1) + benzene (2) + DES(1:4) (3) at constant pressure $(101.325 \mathrm{kPa})$ and constant DES molar fraction $\left(X_{3}=0.1\right)$.

For a better understanding of the fitness of the three thermodynamic models, the coefficient of determination (correlation index, $\mathrm{R}^{2}$ ) is calculated using the following expressions:

$$
\mathrm{R}^{2}=\frac{\mathrm{Q}_{\mathrm{R}}^{\prime}}{\mathrm{Q}_{\Sigma}^{\prime}}=1-\frac{\mathrm{Q}}{\mathrm{Q}_{\Sigma}^{\prime}}=1-\frac{\sum\left(\mathrm{y}_{\mathrm{i}}-\mathrm{u}_{\mathrm{i}}\right)^{2}}{\sum\left(\mathrm{y}_{\mathrm{i}}-\overline{\mathrm{y}}\right)^{2}}
$$


where $y_{i}$ and $u_{i}$ are the experimental data and the estimated value of the vapor phase molar fraction, respectively, and $\bar{y}$ is the average value of the experimental data of the vapor phase molar fraction.

According to Table 8, the NRTL model displays the best fitness. For each system, the correlation index $\mathrm{R}^{2}$ value follows the relation NRTL > UNIQUAC > Wilson, validating that the NRTL model is more suitable for predicting mixtures containing low eutectic solvents. Theoretical analysis demonstrates that the deep eutectic solvent is immiscible with benzene and cyclohexane, and thereby, a miscibility gap is created between the mixed solution resulting in the inefficient correlation by the Wilson model. At the same time, the correlation made by each model for the system containing extractant DES(1:2) is low, but the extraction effect of DES(1:2) is the best. This fact is consistent with the conclusion that the better the extraction effect is, the lower the applicability of the prediction model.

Table 8. Estimated values for the binary parameters using the NRTL model for correlating the pseudo-binary VLE data at a constant DES molar fraction of 0.1 within a pressure of $101.325 \mathrm{kPa}$.

\begin{tabular}{cccccccc}
\hline Extractant & Comp. $\boldsymbol{i}$ & Comp. $\boldsymbol{j}$ & $\boldsymbol{a}_{\boldsymbol{i j}}$ & $\boldsymbol{a}_{\boldsymbol{j} \boldsymbol{i}}$ & $\boldsymbol{b}_{\boldsymbol{i j}}$ & $\boldsymbol{b}_{\boldsymbol{j} i}$ & $\boldsymbol{c}_{\boldsymbol{i j}}$ \\
\hline DES(1:1) & & & -4.2995 & -12.027 & 1605.6 & 4218.2 & -2.7 \\
DES(1:2) & & & -17.895 & 26.168 & 10,000 & $-10,000$ & 0.1717 \\
DES(1:3) & & 23.870 & -11.683 & -7796.4 & 4218.2 & 2.1377 \\
DES(1:4) & & & 56.508 & -17.710 & 52504 & 6357.4 & 0.0306 \\
\hline
\end{tabular}

\subsection{Selection of DES Concentration}

In the process of the selection of HBD and HBA ratios, the results validate that DES(1:2) is the most effective choice from the prepared DESs. Therefore, the concentration of DES(1:2) should be selected next. In the present work, the molar concentrations of $\operatorname{DES}(1: 2)$ is chosen as $0.05,0.10,0.15$, and 0.20 .

\subsubsection{VLE Experiment}

Four kinds of DES(1:2)-cyclohexane-benzene mixture are used to conduct the VLE experiments at $101.325 \mathrm{kPa}$, where the mole concentrations of $\mathrm{DES}(1: 2)$ are $0.05,0.10,0.15$, and 0.20 , respectively.

The results of vapor-liquid equilibrium of the pseudo-ternary systems cyclohexanebenzene-DES(1:2) are summarized in Table 9, where $X_{3}$ is the DES molar fraction in the liquid phase, $X_{1}$ is the cyclohexane molar fraction in the liquid phase, $X^{\prime}{ }_{1}$ is the DES(1:2)free cyclohexane molar fraction in the liquid phase, $Y_{1}$ is the cyclohexane molar fraction in the vapor phase, $T$ is the temperature, $a_{i j}$ is the relative volatility, and $S$ is the selectivity.

At the azeotropic point, the value of the relative volatility obtained will be one, which represents that both components in the mixture have the same vapor pressure. If the azeotrope is not broken, the relative volatility will be lower than one for all concentrations. However, if the azeotrope is broken, the relative volatility becomes higher than one at all concentrations. Table 9 and Figure 9 display that when the DESs are added as entrainers in a molar fraction of 0.05 to 0.2 , the relative volatility $\left(\alpha_{i j}\right)$ of the system with $0.1,0.15$, and 0.2 molar concentrations of DES(1:2) is higher than one at all concentrations, whereas the relative volatility of system with 0.05 molar concentration of DES is lower than one. Figure 10 also depicts the same result, where in the pseudo-ternary system with $0.1,0.15$, and 0.2 molar concentrations of DES(1:2), $Y_{1}$ is greater than $X_{1}$ in all concentrations and, therefore, validates that the azeotrope is broken. 
Table 9. Vapor-liquid equilibrium data of the pseudo-ternary systems cyclohexane (1) + benzene (2) $+\operatorname{DES}(1: 2)$ (3) at a pressure of $101.335 \mathrm{kPa}$.

\begin{tabular}{|c|c|c|c|c|c|c|}
\hline \multicolumn{7}{|c|}{ Cyclohexane (1) + Benzene (2) + DES(1:2) (3) } \\
\hline$X_{3}$ & $X_{1}$ & $X^{\prime}{ }_{1}$ & $Y_{1}$ & $T / K$ & $\alpha_{i j}$ & $S$ \\
\hline 0.05 & 0.0000 & 0.0000 & 0.0000 & 353.25 & - & - \\
\hline 0.05 & 0.0676 & 0.0712 & 0.1325 & 352.32 & 0.5019 & 0.3840 \\
\hline 0.05 & 0.1335 & 0.1405 & 0.1976 & 351.96 & 0.6638 & 0.5079 \\
\hline 0.05 & 0.1993 & 0.2098 & 0.2615 & 351.65 & 0.7498 & 0.5962 \\
\hline 0.05 & 0.3190 & 0.3358 & 0.3649 & 351.13 & 0.8799 & 0.7283 \\
\hline 0.05 & 0.4286 & 0.4512 & 0.4526 & 351.10 & 0.9944 & 1.2083 \\
\hline 0.05 & 0.5045 & 0.5311 & 0.5102 & 351.15 & 1.0874 & 1.3213 \\
\hline 0.05 & 0.6382 & 0.6718 & 0.6352 & 351.30 & 1.1756 & 1.4284 \\
\hline 0.05 & 0.7273 & 0.7656 & 0.7192 & 351.77 & 1.2752 & 1.6397 \\
\hline 0.05 & 0.7849 & 0.8262 & 0.7841 & 352.20 & 1.3089 & 1.7847 \\
\hline 0.05 & 0.8450 & 0.8895 & 0.8513 & 352.73 & 1.4061 & 1.9172 \\
\hline 0.05 & 0.9500 & 1.0000 & 1.0000 & 353.85 & - & - \\
\hline$X_{3}$ & $X_{1}$ & $X^{\prime}{ }_{1}$ & $Y_{1}$ & $T / K$ & $\alpha_{i j}$ & $S$ \\
\hline 0.1 & 0.0000 & 0.0000 & 0.0000 & 353.25 & - & - \\
\hline 0.1 & 0.1668 & 0.1853 & 0.3191 & 351.20 & 2.0601 & 1.7051 \\
\hline 0.1 & 0.2406 & 0.2673 & 0.4939 & 350.64 & 2.6752 & 2.4107 \\
\hline 0.1 & 0.3015 & 0.3351 & 0.6053 & 351.28 & 3.0438 & 3.6984 \\
\hline 0.1 & 0.3529 & 0.3921 & 0.7107 & 351.74 & 3.8089 & 4.8976 \\
\hline 0.1 & 0.4507 & 0.5008 & 0.8091 & 352.34 & 4.2229 & 5.7580 \\
\hline 0.1 & 0.5597 & 0.6219 & 0.8868 & 352.67 & 4.7632 & 6.4947 \\
\hline 0.1 & 0.7232 & 0.8035 & 0.9420 & 353.17 & 3.9681 & 5.4106 \\
\hline 0.1 & 0.9000 & 1.0000 & 1.0000 & 353.85 & - & - \\
\hline$X_{3}$ & $X_{1}$ & $X^{\prime}{ }_{1}$ & $Y_{1}$ & $T / K$ & $\alpha_{i j}$ & $S$ \\
\hline 0.15 & 0.0000 & 0.0000 & 0.0000 & 353.25 & - & - \\
\hline 0.15 & 0.0780 & 0.0918 & 0.1920 & 351.20 & 2.3509 & 1.9458 \\
\hline 0.15 & 0.1346 & 0.1583 & 0.3311 & 350.64 & 2.6319 & 2.3717 \\
\hline 0.15 & 0.2360 & 0.2777 & 0.5393 & 351.28 & 3.0448 & 3.6996 \\
\hline 0.15 & 0.2824 & 0.3322 & 0.6154 & 351.74 & 3.2166 & 4.1360 \\
\hline 0.15 & 0.3827 & 0.4502 & 0.7380 & 352.34 & 3.4400 & 4.6905 \\
\hline 0.15 & 0.4338 & 0.5103 & 0.7870 & 352.67 & 3.5457 & 4.8346 \\
\hline 0.15 & 0.5195 & 0.6112 & 0.8413 & 352.96 & 3.3722 & 4.5980 \\
\hline 0.15 & 0.6038 & 0.7104 & 0.9011 & 353.13 & 3.7143 & 5.0645 \\
\hline 0.15 & 0.7020 & 0.8259 & 0.9589 & 353.40 & 4.9182 & 6.7060 \\
\hline 0.15 & 0.8500 & 1.0000 & 1.0000 & 353.85 & - & - \\
\hline$X_{3}$ & $X_{1}$ & $X^{\prime}{ }_{1}$ & $Y_{1}$ & $T / K$ & $\alpha_{i j}$ & $S$ \\
\hline 0.2 & 0.0000 & 0.0000 & 0.0000 & 353.25 & - & - \\
\hline 0.2 & 0.0862 & 0.1077 & 0.1845 & 352.35 & 1.8747 & 1.4345 \\
\hline 0.2 & 0.1477 & 0.1846 & 0.3432 & 351.35 & 2.3081 & 2.1979 \\
\hline 0.2 & 0.1776 & 0.2220 & 0.4209 & 351.04 & 2.5471 & 2.3257 \\
\hline 0.2 & 0.2117 & 0.2647 & 0.4924 & 351.00 & 2.6953 & 4.1499 \\
\hline 0.2 & 0.2844 & 0.3555 & 0.6403 & 351.67 & 3.2274 & 4.6699 \\
\hline 0.2 & 0.3298 & 0.4123 & 0.7141 & 351.96 & 3.5603 & 4.8545 \\
\hline 0.2 & 0.4302 & 0.5377 & 0.8061 & 352.33 & 3.5747 & 4.8741 \\
\hline 0.2 & 0.4735 & 0.5919 & 0.8410 & 352.67 & 3.6459 & 4.9712 \\
\hline 0.2 & 0.5254 & 0.6567 & 0.8672 & 353.00 & 3.4121 & 4.6524 \\
\hline 0.2 & 0.6498 & 0.8123 & 0.9425 & 353.56 & 3.7876 & 4.4239 \\
\hline 0.2 & 0.8000 & 1.0000 & 1.0000 & 353.85 & - & - \\
\hline
\end{tabular}






Figure 9. Experimental $X^{\prime} Y$ diagram for the pseudo-ternary systems (cyclohexane (1) + benzene (2) + $\operatorname{DES}(1: 2)(3))$ at atmospheric pressure and constant DES molar fraction $\left(X_{3}=0.1\right)$, and the experimental XY diagram for binary system (cyclohexane (1) + benzene (2)).

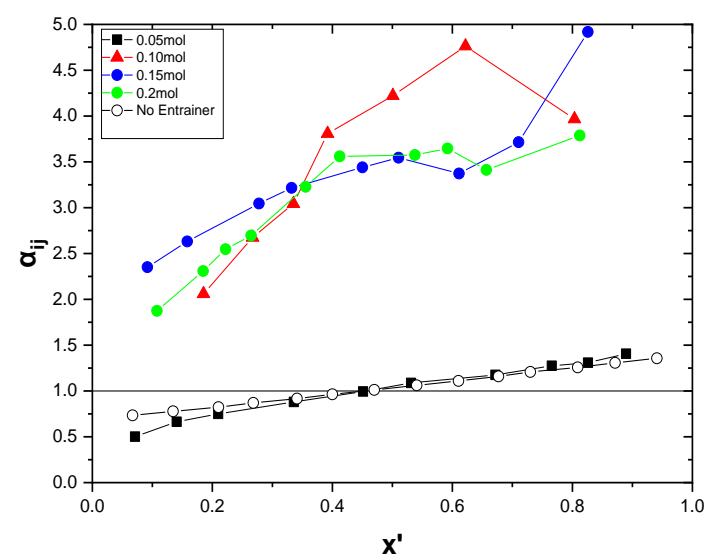

Figure 10. Experimental relative volatility $\left(a_{i j}\right)$ of the pseudo-ternary system cyclohexane $(1)+$ benzene (2) + DES(1:2) (3) and binary system cyclohexane (1) + benzene (2).

\subsubsection{VLE DATA Correlation}

In most cases of DES(1:2) molar concentration, the NRTL model shows the best fitness. The coefficient of determination value $\left(\mathrm{R}^{2}\right)$ follows the trend NRTL $>$ UNIQUAC $>$ Wilson in Table 10. The model regression results for different molar concentrations of DES(1:2) are shown in Figures 11-14. The results depicted from the Figure 15 are also in accordance with the data of the relative volatility $\left(\alpha_{i j}\right)$ in Table 11 . In the system added with $0.1,0.15$, and 0.2 molar concentrations of DES(1:2), the azeotrope is broken. For each system, the two binary interaction parameters of cyclohexane/benzene through the NRTL model are obtained, which are shown in Table 11.

Table 10. Coefficient of determination $\left(\mathrm{R}^{2}\right)$ of the pseudo-ternary systems fitting using the three thermodynamic models.

\begin{tabular}{cccc}
\hline DES System & \multicolumn{3}{c}{$\mathbf{R}^{\mathbf{2}}$} \\
\hline DES(1:2) mole concentration & UNIQUAC & WILSON & NRTL \\
\hline 0.05 & 0.999274739 & 0.999161341 & 0.999263945 \\
0.10 & 0.823243826 & 0.615250142 & 0.877053812 \\
0.15 & 0.691208105 & 0.691251575 & 0.725252503 \\
0.20 & 0.708145398 & 0.692945634 & 0.818531606 \\
\hline
\end{tabular}




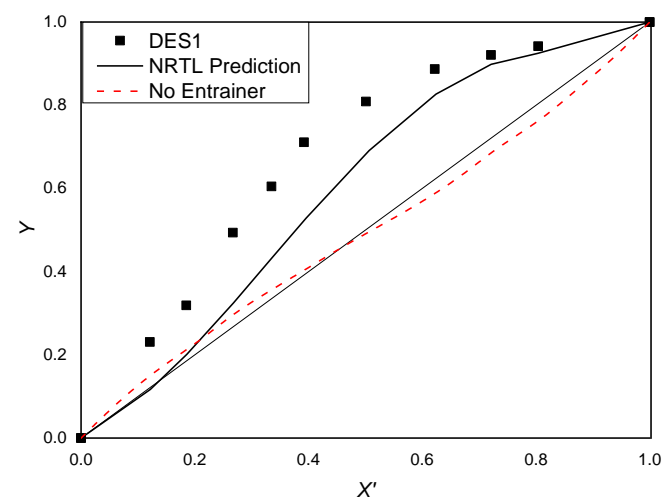

Figure 11. Experimental and calculated data $X^{\prime} Y$ diagram for cyclohexane (1) + benzene (2) + DES (3) at constant pressure $(101.325 \mathrm{kPa})$ and constant DES molar fraction $\left(X_{3}=0.1\right)$.

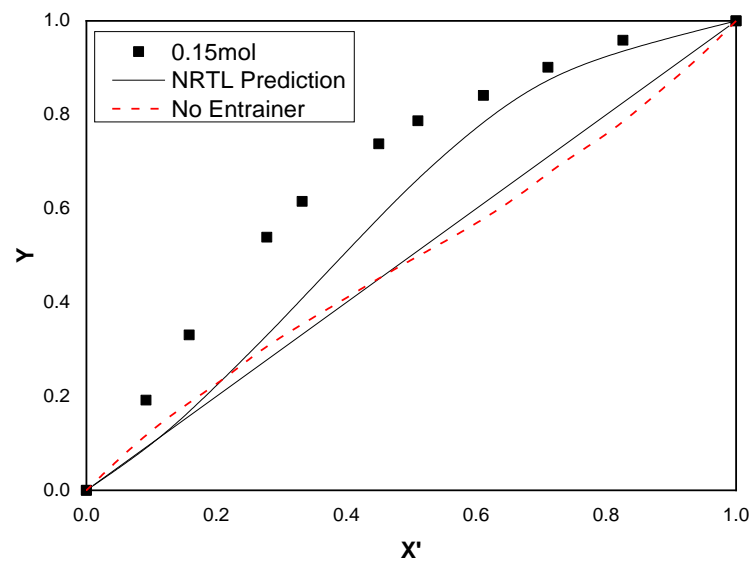

Figure 12. Experimental and calculated data $X^{\prime} Y$ diagram for cyclohexane (1) + benzene (2) + DES (3) at constant pressure $(101.325 \mathrm{kPa})$ and constant DES molar fraction $\left(X_{3}=0.15\right)$.

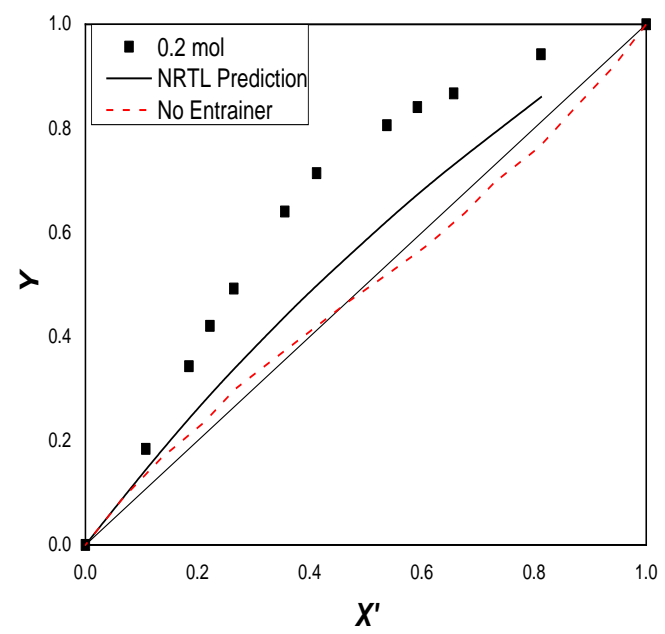

Figure 13. Experimental and calculated data $X^{\prime} Y$ diagram for cyclohexane (1) + benzene (2) + DES (3) at constant pressure $(101.325 \mathrm{kPa})$ and constant DES molar fraction $\left(X_{3}=0.2\right)$. 


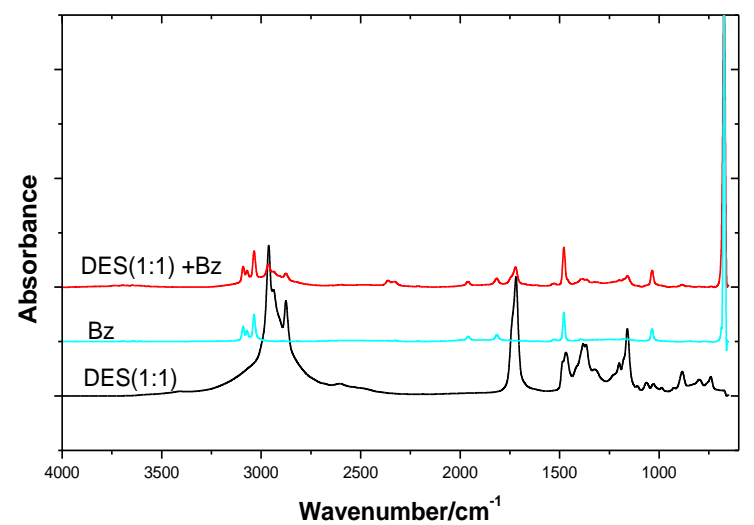

Figure 14. FT - IR spectra of DES(1:1), benzene and DES(1:1) + benzene(DES 0.1 (molar concentration)).

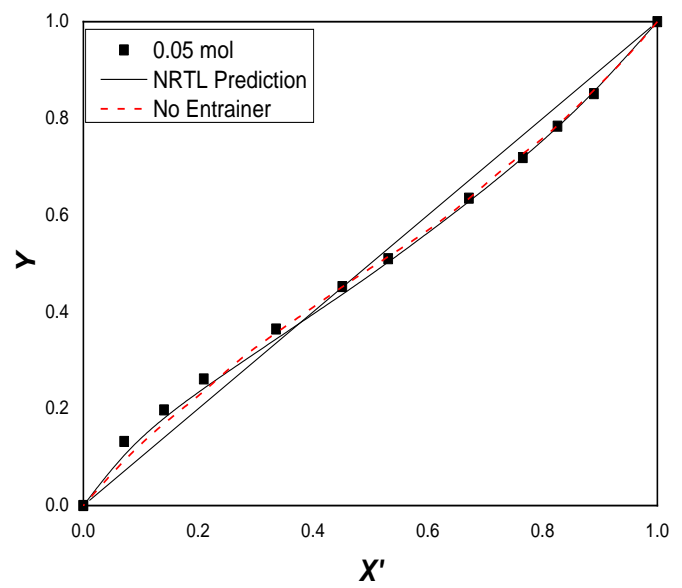

Figure 15. Experimental and calculated data $X^{\prime} Y$ diagram for cyclohexane (1) + benzene (2) + DES (3) at constant pressure $(101.325 \mathrm{kPa})$ and DES molar fraction $\left(X_{3}=0.05\right)$.

Table 11. Estimated values for the binary parameters using the NRTL model for correlating the pseudo-binary VLE data.

\begin{tabular}{cccccccc}
\hline DES(1:2) Mole Concentration & Comp. $\boldsymbol{i}$ & Comp. $\boldsymbol{j}$ & $\boldsymbol{a}_{\boldsymbol{i j}}$ & $\boldsymbol{a}_{\boldsymbol{j i}}$ & $\boldsymbol{b}_{\boldsymbol{i j}}$ & $\boldsymbol{b}_{\boldsymbol{j i}}$ & $\boldsymbol{c}_{\boldsymbol{i}}$ \\
\hline 0.05 & & & 5.7781 & 21.790 & -2897.1 & -6397.7 & -2.7 \\
0.10 & & & -17.895 & 26.168 & 10,000 & $-10,000$ & 0.1717 \\
0.15 & Cyclohexane & Benzene & -16.288 & 27.070 & 10,000 & $-10,000$ & 2.1377 \\
0.2 & & & -20.707 & -20.290 & 10,000 & 1000 & 0.0306 \\
\hline
\end{tabular}

\subsection{Extractive Distillation Mechanism}

Extraction mechanisms are very important to understand the extractive distillation process and will provide significant insights for the development of molecule design and the smart design of DES entrainers. FT-IR and NMR are employed to elucidate the extraction mechanism. In the present research, benzene acts as the heavy component and is kept at the bottom along with DESs, where the interaction of benzene and DESs is studied.

\subsubsection{Selection of HBD and HBD Ratio}

FT-IR analysis is used to elucidate the mechanism for the process of selection of HBD and HBD ratios and to validate the results of the selection. The infrared spectrograms of the test samples are provided in Figures 16-18. 


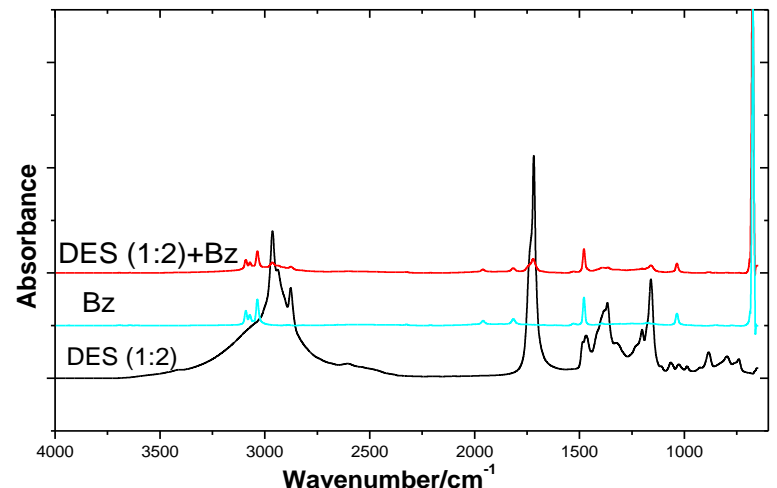

Figure 16. FT - IR spectra of DES(1:2), benzene and DES(1:2) + benzene(DES 0.1 (molar concentration)).

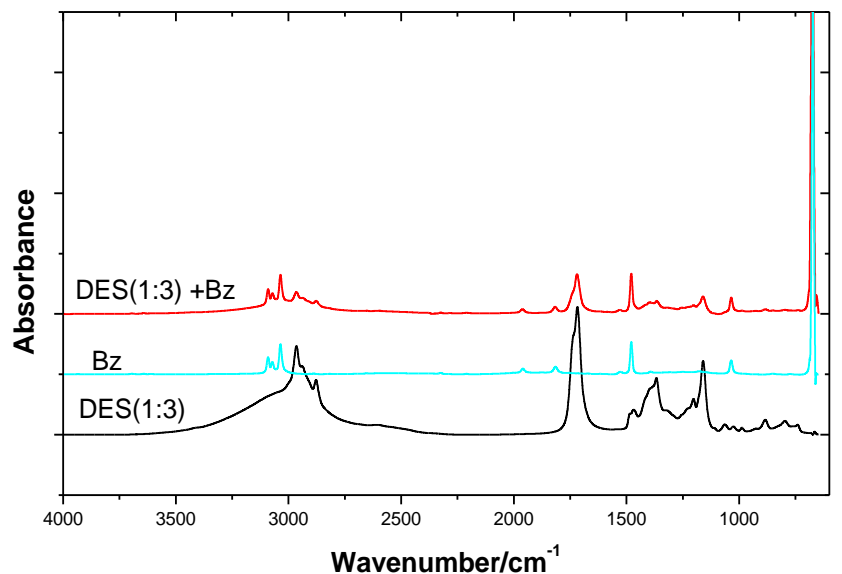

Figure 17. FT-IR spectra of DES(1:3), benzene and DES(1:3) + benzene(DES 0.1 (molar concentration)).

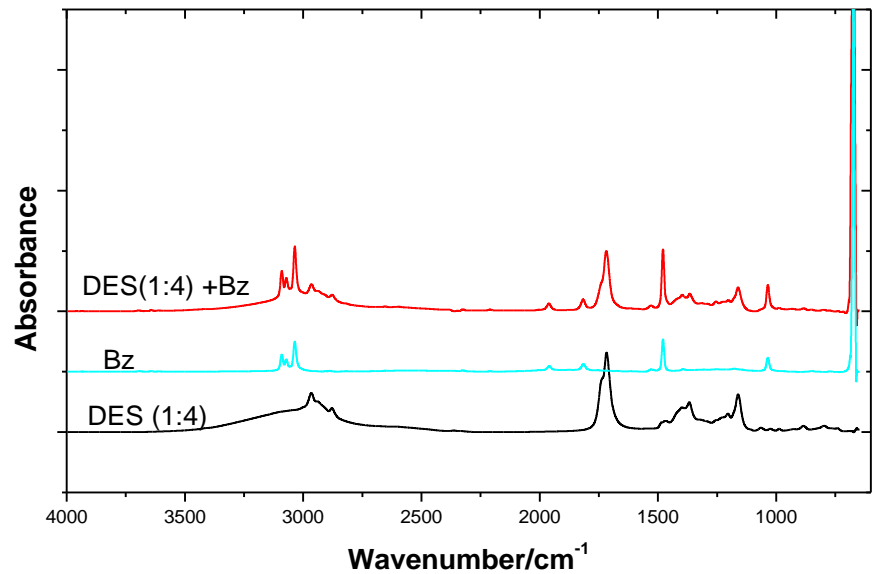

Figure 18. FT - IR spectra of DES(1:4), benzene and DES(1:4) + benzene(DES 0.1 (molar concentration)).

From Figure 17, the FT-IR spectra of DES(1:1-1:4), benzene and DES(1:1-1:4) + benzene shows the peak corresponding to the hydroxy $\mathrm{v}(\mathrm{OH})$ group at $3200 \mathrm{~cm}^{-1}$ and the peak ascribed to the carboxyl group $\mathrm{v}(\mathrm{C}=\mathrm{O})$ at $1722 \mathrm{~cm}^{-1}$. In the mixture containing $\mathrm{DES}(1: 1-1: 4)$ + benzene, the hydroxy and carboxy peaks become weaker. This fact is attributed to the formation of hydrogen bond and $\pi-\pi$ bond interaction between DES(1:1-1:4) and benzene that have destroyed the hydrogen bond within the DES(1:1-1:4) system, and subsequently, the strength of each system is found to be different due to different molar ratios. The results validate that the $\mathrm{C}=\mathrm{O}$ double bond in LA of DES interacts with benzene by forming a $\pi-\pi$ 
bond, and the O-H bond in LA of DES interacts with benzene by forming the hydrogen bond. However, the change in peak intensity of DES(1:2) is the largest, substantiating that the hydrogen bond and $\pi-\pi$ bond interaction between DES(1:2) and benzene is the strongest, leading to the breaking of the azeotrope.

\subsubsection{Selection of DES Concentration}

Since the change in concentration of the constituents cannot be exactly revealed by FT-IR analysis, NMR is employed in the selection of the DES concentration study. Using ChemDraw software, the magnetic resonance hydrogen spectrum of tetrabutylammonium bromide, levulinic acid, and benzene is simulated, and chemical shift values are obtained, as shown in Figures 19-21. The experimental test of ${ }^{1} \mathrm{H}$ NMR spectra and magnified view of a particular range are shown in Figures 22 and 23. From Figures 21 and 22, it is inferred that the NMR spectrum simulated from the ChemDraw software highly corroborates with the test measured spectra, confirming that the test samples are highly pure and they are target material.

\section{ChemNMR ${ }^{1} \mathrm{H}$ Estimation}

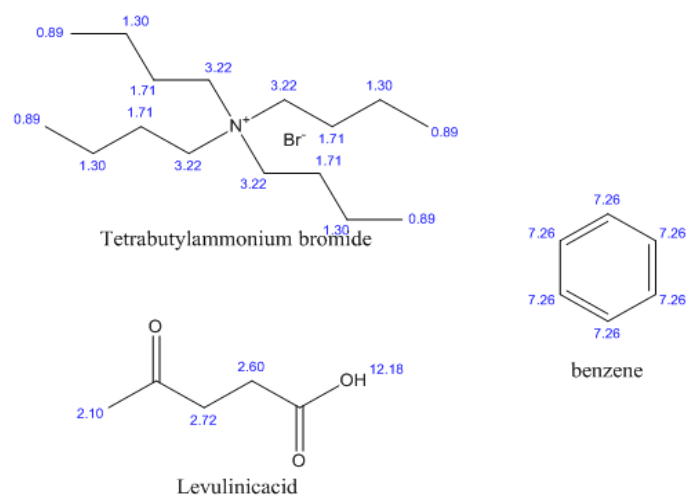

Figure 19. Chemical shift values of intramolecular hydrogen atoms of TBAB, LA, and benzene estimated by ChemDraw.

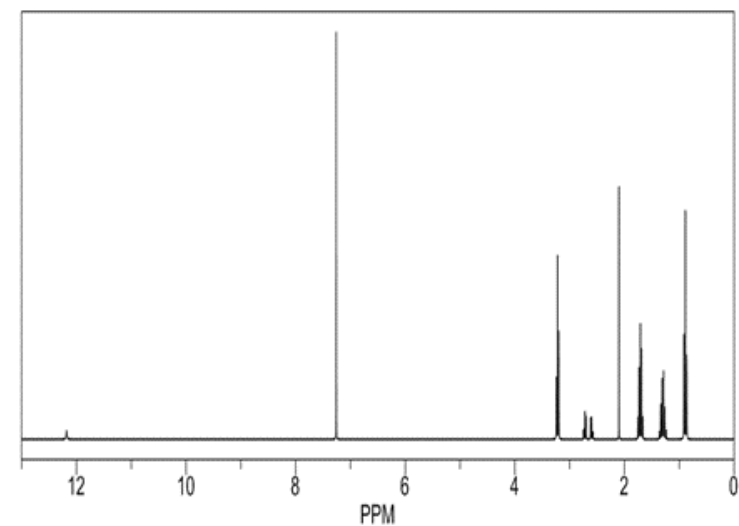

Figure 20. ${ }^{1} \mathrm{H}$ NMR of TBAB, LA and benzene estimated by ChemDraw. 




Figure 21. ${ }^{1} \mathrm{H}$ NMR of different molar ratios DES(1:2) and benzene (the DES mole concentrations are $1,0.05,0.1,0.15$, and 0.2 from the bottom up, respectively).



Figure 22. A part of a larger view of Figure 21.

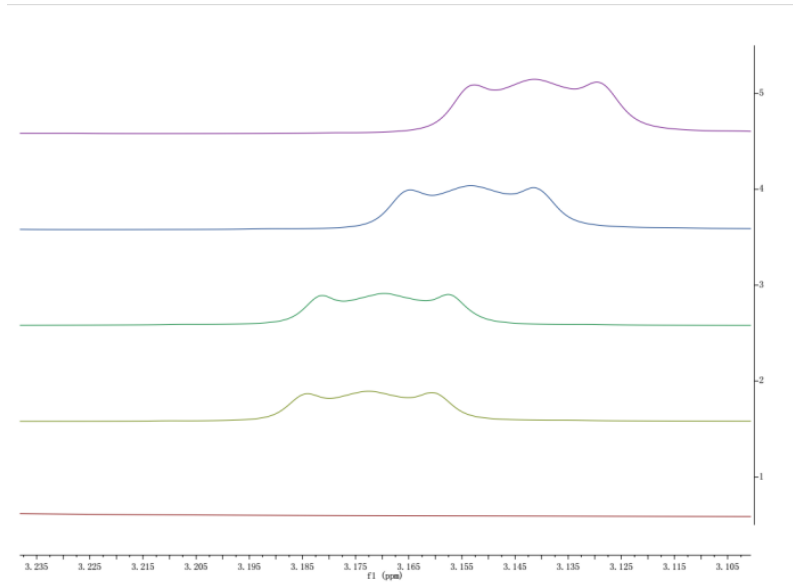

Figure 23. A part of a larger view of Figure 22.

From the expanded spectra shown in Figures 22 and 23, it is inferred that compared to pure DES(1:2), different concentrations of DES(1:2) all have apparent spectral peak shifts and are shifted towards the low field. This is ascribed to the formation of hydrogen bonds between different concentrations of DES(1:2) and benzene. As a result, the electron cloud density around the hydrogen nucleus has declined due to the induced effect. As can be seen from Figure 23, the chemical shift of spectral peak offset value is different for 
different concentrations of DES(1:2); the offset distance is positively correlated with the DES(1:2) concentration. This substantiates that the hydrogen bonding strength formed between different concentrations of DES(1:2) and benzene is different, and it is positively correlated with the concentration. From these interpretations of the NMR results, the vapor-liquid equilibrium results are verified, i.e., low concentrations of DES(1:2) cannot break the benzene-cyclohexane azeotrope, but high concentrations of DES can break the azeotrope.

\section{Conclusions}

The eutectic solvent is prepared, and its physical properties are characterized. Through the vapor-liquid phase equilibrium experiments, the X-Y phase diagram and relative volatility diagram are compared, and the optimal HBA and HBD molar ratio and optimal molar concentration are estimated as 1:2 and 0.1, respectively. Other DES systems changed the azeotropic point but did not break the azeotrope. The results show that the extraction effect of DES is dependent on the system to be separated, the type and ratio of DES, and the DES concentration.

Here, three thermodynamic models are used to fit vapor-liquid phase equilibrium data. By comparing the model-related indices $\left(R^{2}\right)$, the correlation degree of the NRTL model is found to be the highest, and the binary interaction parameters of each system are obtained. The results proved the NTRL model is more suitable for predicting the vapor-liquid equilibrium behavior of a system containing DESs. In the best extraction system, cyclohexane-DES(1:2) (molar concentration 0.1) system, $\mathrm{R}^{2}$ is 0.8771 , NRTL model binary interaction parameters: $a_{i j},-17.895 ; a_{j i}, 26.168 ; b_{i j}, 10000 ; b_{j i},-10000 ; c_{i j}, 0.1717$ ( $i=$ cyclohexane, $j=$ benzene).

The screening and optimized results of DES are verified by FT-IR and NMR analyses. It is proven that there is a formation of a strong hydrogen bond and $\pi-\pi$ bond between benzene and DES with an extraction effect, and this effect can break the azeotrope. There are weak or no obvious hydrogen bonds and $\pi-\pi$ bonds between benzene and DES without an extraction effect, and some can only change the azeotropic point but cannot break the azeotrope. These interpretations substantiate the results of the vapor-liquid phase equilibrium experiments. Combined with thermodynamics research, the present work provides a theoretical basis for the design and optimization of DES.

Author Contributions: Conceptualization, F.B., C.H. and Y.B.; methodology, F.B.; validation, F.B.; investigation, F.B. and M.M.; analysis guidance, Y.B.; writing original draft preparation, F.B.; writingreview and editing, F.B. and M.M.; supervision, C.H. All authors have read and agreed to the published version of the manuscript.

Funding: This research was funded by The National Key Research and Development Program of China, grant number 2019YFC1907600; Supported by the Innovation Academy for Green Manufacture, Chinese Academy of Sciences, grant number IAGM2020C08; and Regional Key Projects of Science and Technology Service network Program (STS), Chinese Academy of Sciences, grant number KFJ-STS-QYZD-2021-14-002.

Institutional Review Board Statement: Not applicable.

Informed Consent Statement: Not applicable.

Data Availability Statement: Not applicable.

Conflicts of Interest: The authors declare no conflict of interest. 


\section{References}

1. Abbott, A.P.; Capper, G.; Davies, D.; Rasheed, R.K.; Tambyrajah, V. Novel solvent properties of choline chloride/urea mixturesElectronic supplementary information (ESI). Chem. Commun. 2002, 70-71. Available online: http://www.rsc.org/suppdata/cc/b2 /b210714g/ (accessed on 21 September 2021). [CrossRef]

2. Francisco, M.; González, A.S.B.; De Dios, S.L.G.; Weggemans, W.; Kroon, M.C. Comparison of a low transition temperature mixture (LTTM) formed by lactic acid and choline chloride with choline lactate ionic liquid and the choline chloride salt: Physical properties and vapour-liquid equilibria of mixtures containing water and ethanol. RSC Adv. 2013, 3, 23553-23561. [CrossRef]

3. Durand, E.; Lecomte, J.; Villeneuve, P. From green chemistry to nature: The versatile role of low transition temperature mix-tures. Biochimie 2016, 120, 119-123. [CrossRef]

4. Zeng, Q.; Wang, Y.; Huang, Y.; Ding, X.; Chen, J.; Xu, K. Deep eutectic solvents as novel extraction media for protein partitioning. Analyst 2014, 139, 2565-2573. [CrossRef]

5. Hadi, N.A.; Ng, M.H.; Choo, Y.M.; Hashim, M.A.; Jayakumar, N.S. Performance of Choline-Based Deep Eutectic Solvents in the Extraction of Tocols from Crude Palm Oil. J. Am. Oil Chem. Soc. 2015, 92, 1709-1716. [CrossRef]

6. Li, J.; Han, Z.G.; Zou, Y.P.; Yu, B. Efficient extraction of major catechins in Camellia sinensis leaves using green choline chlo-ridebased Deep Eutectic Solvents. Rsc. Adv. 2015, 5, 93937-93944. [CrossRef]

7. Li, N.; Wang, Y.; Xu, K.; Huang, Y.; Wen, Q.; Ding, X. Development of green Betaine-Based Deep Eutectic Solvent aqueous two-phase system for the extraction of protein. Talanta 2016, 152, 23-32. [CrossRef]

8. Paradiso, V.M.; Clemente, A.; Summo, C.; Pasqualone, A.; Caponio, F. Towards green analysis of virgin olive oil phenolic compounds: Extraction by a natural deep eutectic solvent and direct spectrophotometric detection. Food Chem. 2016, 212, 43-47. [CrossRef]

9. Qi, X.-L.; Peng, X.; Huang, Y.-Y.; Li, L.; Wei, Z.-F.; Zu, Y.-G.; Fu, Y.-J. Green and efficient extraction of bioactive flavonoids from Equisetum palustre L. by deep eutectic solvents-based negative pressure cavitation method combined with macroporous resin enrichment. Ind. Crop. Prod. 2015, 70, 142-148. [CrossRef]

10. Wei, Z.-F.; Wang, X.-Q.; Peng, X.; Wang, W.; Zhao, C.-J.; Zu, Y.-G.; Fu, Y.-J. Fast and green extraction and separation of main bioactive flavonoids from Radix Scutellariae. Ind. Crop. Prod. 2015, 63, 175-181. [CrossRef]

11. Gonzalez, A.S.B.; Francisco, M.; Dios, S.L.G.D.; Kroon, M.C. Liquid-liquid equilibrium data for the systems \{LTTM plus benzene plus hexane\} and \{LTTM plus ethyl acetate plus hexane\} at different temperatures and atmospheric pressure. Fluid Phase Equilibria 2013, 360, 54-62. [CrossRef]

12. Zhang, H.; Tang, B.; Row, K. Extraction of Catechin Compounds from Green Tea with a New Green Solvent. Chem. Res. Chin. Univ. 2014, 30, 37-41. [CrossRef]

13. Hou, Y.; Li, J.; Ren, S.; Niu, M.; Wu, W. Separation of the Isomers of Benzene Poly (carboxylic acid) s by Quaternary Ammonium Salt via Formation of Deep Eutectic Solvents. J. Phys. Chem. B 2014, 118, 13646-13650. [CrossRef]

14. Hou, Y.; Li, Z.; Ren, S.; Wu, W. Separation of toluene from toluene/alkane mixtures with phosphonium salt based deep eutectic solvents. Fuel Process. Technol. 2015, 135, 99-104. [CrossRef]

15. Jiao, T.; Zhuang, X.; He, H.; Li, C.; Chen, H.; Zhang, S. Separation of Phenolic Compounds from Coal Tar via Liquid-Liquid Extraction Using Amide Compounds. Ind. Eng. Chem. Res. 2015, 54, 2573-2579. [CrossRef]

16. Kareem, M.A.; Mjalli, F.S.; Hashim, M.A.; AlNashef, I.M. Liquid-liquid equilibria for the ternary system (phosphonium based deep eutectic solvent-benzene-hexane) at different temperatures: A new solvent introduced. Fluid Phase Equilibria 2012, 314, 52-59. [CrossRef]

17. Kareem, M.A.; Mjalli, F.S.; Hashim, M.A.; Hadj-Kali, M.K.; Bagh, F.S.G.; Al Nashef, I. Phase equilibria of toluene/heptane with tetrabutylphosphonium bromide based deep eutectic solvents for the potential use in the separation of aromatics from naphtha. Fluid Phase Equilibria 2012, 333, 47-54. [CrossRef]

18. Maugeri, Z.; Leitner, W.; de María, P.D. Practical separation of alcohol-ester mixtures using Deep-Eutectic-Solvents. Tetrahedron Lett. 2012, 53, 6968-6971. [CrossRef]

19. Oliveira, F.S.; Pereiro, A.B.; Rebelo, L.P.; Marrucho, I. Deep eutectic solvents as extraction media for azeotropic mixtures. Green Chem. 2013, 15, 1326-1330. [CrossRef]

20. Hizaddin, H.F.; Hadj-Kali, M.K.; Ramalingam, A.; Hashim, M.A. Extraction of nitrogen compounds from diesel fuel using imidazolium- and pyridinium-based ionic liquids: Experiments, COSMO-RS prediction and NRTL correlation. Fluid Phase Equilibria 2015, 405, 55-67. [CrossRef]

21. Hizaddin, H.F.; Hadj-Kali, M.K.; Ramalingam, A.; Hashim, M.A. Extractive denitrogenation of diesel fuel using ammonium- and phosphonium-based deep eutectic solvents. J. Chem. Thermodyn. 2015, 95, 164-173. [CrossRef]

22. Khezeli, T.; Daneshfar, A.; Sahraei, R. A green ultrasonic-assisted liquid-liquid microextraction based on Deep Eutectic Solvent for the HPLC-UV determination of ferulic, caffeic and cinnamic acid from olive, almond, sesame and cinnamon oil. Talanta 2016, 150, 577-585. [CrossRef]

23. Zhang, Y.; Li, Z.; Wang, H.; Xuan, X.; Wang, J. Efficient separation of phenolic compounds from model oil by the formation of choline derivative-based deep eutectic solvents. Sep. Purif. Technol. 2016, 163, 310-318. [CrossRef]

24. Hadj-Kali, M.K.; Mulyono, S.; Hizaddin, H.F.; Wazeer, I.; El-Blidi, L.; Ali, E.; Hashim, M.A.; AlItashef, I.M. Removal of Thi-ophene from Mixtures with n-Heptane by Selective Extraction Using Deep Eutectic Solvents. Ind. Eng. Chem. Res. 2016, 55, 8415-8423. [CrossRef] 
25. Li, C.; Li, D.; Zou, S.; Li, Z.; Yin, J.; Wang, A.; Cui, Y.; Yao, Z.; Zhao, Q. Extraction desulfurization process of fuels with ammonium-based deep eutectic solvents. Green Chem. 2013, 15, 2793-2799. [CrossRef]

26. Li, C.; Zhang, J.; Li, Z.; Yin, J.; Cui, Y.; Liu, Y.; Yang, G. Extraction desulfurization of fuels with 'metal ions' based deep eutectic solvents (MDESs). Green Chem. 2016, 18, 3789-3795. [CrossRef]

27. Rodriguez, N.R.; Kroon, M.C. Isopropanol dehydration via extractive distillation using low transition temperature mixtures as entrainers. J. Chem. Thermodyn. 2015, 85, 216-221. [CrossRef]

28. Gjineci, N.; Boli, E.; Tzani, A.; Detsi, A.; Voutsas, E. Separation of the ethanol/water azeotropic mixture using ionic liquids and deep eutectic solvents. Fluid Phase Equilibria 2016, 424, 1-7. [CrossRef]

29. Abbott, A.P.; Boothby, D.; Capper, G.; Davies, D.; Rasheed, R.K. Deep Eutectic Solvents Formed between Choline Chloride and Carboxylic Acids: Versatile Alternatives to Ionic Liquids. J. Am. Chem. Soc. 2004, 126, 9142-9147. [CrossRef]

30. Mi, W.; Tong, R.; Hua, C.; Yue, K.; Jia, D.; Lu, P.; Bai, F. Vapor-liquid equilibrium data for binary systems of N, Ndimethylacetamide with cyclohexene, cyclohexane, and benzene separately at atmospheric pressure. J. Chem. Eng. Data 2015, 60, 3063-3068. [CrossRef]

31. Bai, F.; Hua, C.; Li, J. Separation of Benzene-Cyclohexane Azeotropes via Extractive Distillation Using Deep Eutectic Solvents as Entrainers. Processes 2021, 9, 336. [CrossRef] 